\title{
EFFECT OF ETHANOL ON PERFORMANCE AND DURABILITY OF A DIESEL COMMON RAIL HIGH PRESSURE FUEL PUMP
}

\author{
Tomas Mickevičius, Stasys Slavinskas, Raimondas Kreivaitis \\ Institute of Power and Transport Machinery Engineering, Aleksandras Stulginskis University, \\ Akademija, Kaunas District, Lithuania
}

Submitted 30 January 2015; resubmitted 12 March 2015, 21 April 2015; accepted 13 May 2015;

first published online 13 July 2015

\begin{abstract}
This paper presents a comparative experimental study for determining the effect of ethanol on functionality of a high pressure pump of the common rail fuel injection system. For experimental durability tests were prepared two identical fuel injection systems, which were mounted on a test bed for a fuel injection pump. One of the fuel injection systems was feed with diesel fuel; other fuel injection system was fuelled with ethanol-diesel fuel blend. A blend with $12 \% \mathrm{v} / \mathrm{v}$ ethanol and $88 \% \mathrm{v} / \mathrm{v}$ diesel fuel and low sulphur diesel fuel as a reference fuel were used in this study. To determine the effect of ethanol on the durability of the high pressure pump total fuel delivery performance and surface roughness of pump element were measured prior and after the test. Results show that the use of the ethanol-diesel blend tested produced a negative effect on the durability of the high pressure fuel pump. The wear of plungers and barrels when using ethanol-diesel fuel blend caused a decrease in fuel delivery up to $30 \%$ after $100 \mathrm{~h}$ of operation.
\end{abstract}

Keywords: diesel fuel; ethanol-diesel blend; common rail injection system; durability; lubricity; surface roughness.

\section{Introduction}

Unstable oil prices and decreasing fossil fuel reserves around the world encouraged to pay attention to usage of renewable and alternative energy sources. On the other hand, this need is also conditioned by environmental requirements. In the EU, transport accounts for $21 \%$ of all greenhouse gas emissions contributing to global warming, and this number is constantly growing. Therefore, in the document of the European Commission, the White Paper: Roadmap to a Single European Transport Area (EC 2011), one of the directions is developing and deploying sustainable fuels, improving the energy efficiency performance of vehicles across all modes, and reaching the $60 \%$ emission reduction in the transport system.

In the European Union, rapeseed oil remains the main raw material used in the production of biodiesel, making the source for production of about $84 \%$ of biodiesel. In order to expand the base of raw materials and to increase the share of renewable energy in diesel fuel, recently interest in the potential use of bio-ethanol in diesel engines increased. Bio-ethanol can be produced from a number of crops, including sugarcane, corn (maize), wheat and sugar beet. The last two are currently the main sources of ethanol in Europe (Edwards et al. 2001).

However, it should be emphasized that when mineral fuels are replaced with biofuels or alternative fuels, physical and chemical properties of fuel change. These are the properties affecting injection characteristics, the autoignation delay, combustion and heat release in the cylinder, which cause consequent changes in comparative effective fuel consumption in the engine, indicatory and effective characteristics of the engine, exhaust emissions and smoke opacity.

The chemical structure and injection characteristics of fuel significantly affect the autoignition delay, since they influence the change of temperature of the mixture at the end of pressure period before the upper endpoint. The experimental tests have shown that ethanol prolongs the autoignition delay and increases the maximum gas pressure inside the cylinder (Rakopoulos et al. 2014). When increasing the amount of ethanol in diesel fuel, the cetane number, which is significantly lower for ethanol (5-8) than diesel fuel, is reduced correspondingly ( $\mathrm{Li}$ et al. 2005). However, the period of autoignition delay of diesel fuel and especially synthetic biofuel does not always directly depend on the cetane number (Labeckas, 
Slavinskas 2013). The autoignition delay depends on the engine's physical conditions, i.e. pressure and temperature inside the cylinder.

The experiments conducted by scientists show that the ethanol additive in diesel fuel increases fuel consumption of the engine and thermal efficiency of the engine (Lapuerta et. al 2008). Ethanol has a lower calorific value than diesel fuel. The lower calorific value of diesel fuel is $41.8 \mathrm{MJ} / \mathrm{kg}$ to $44 \mathrm{MJ} / \mathrm{kg}$, and that of etha$\mathrm{nol}$ is $27.22 \mathrm{MJ} / \mathrm{kg}$, therefore mixing ethanol into diesel fuel decreases net calorific value of fuel blend, resulting in increased fuel consumption. It is worth noting that the usage of oxygen additives in diesel engines, despite rising brake specific fuel consumption compared with the engine running on diesel fuel, slightly increases the engine's brake thermal efficiency in the most load and speed modes (Kim, Choi 2008). A higher engine's brake thermal efficiency in research works was explained by the fact that oxygen contained in biofuels improves fuel combustion in the engine. Ethanol-diesel blends up to $20 \%$ can be used in constant speed CI engines without any modification (Agarwal 2007; Hansen et al. 2005).

Due to the lower density of ethanol fuel, start of injection may be delayed, as less fuel is injected into the cylinder. It was found that the ethanol part in the fuel causes a lag of fuel injection of 2-6 CA (Lebedevas et al. 2013). Dernotte et al. (2011) presents an experimental investigation of the influence of fuel density and fuel viscosity on the flow characteristics and on the spray development process generated from a high pressure diesel injector. Results show that increasing fuel viscosity leads to a decrease of the discharge coefficient for low injection pressures while density is the main parameter driving the mass flow rate. The spray pattern is also affected since dense and viscous fuels tend to induce a longer spray tip penetration with a more narrow spray angle. Torres-Jimenez et al. (2011a) experimentally investigated fuel injection characteristics of bioethanol-diesel fuel (up to $15 \%$ bioethanol) with the aim of finding the variations in those parameters compared to their respective pure fuel values. Results indicate that increasing bioethanol in diesel fuel shows no significant variations or a slightly increase in fuelling, injection timing, injection duration, and mean injection rate and a decrease in injection delay and maximum injection pressure, compared to pure diesel fuel. Investigation was performed on an in-line fuel injection $M$ type system.

Blends of ethanol and diesel fuels demonstrate a lower viscosity of biofuels (De Menezes et al. 2006). Decrease in fuel viscosity changes the injection spray parameters, decreasing the spray penetration and increasing its initial angle. Kajdas and Majzner (2001) investigated the influence of the fraction composition of diesel fuel on the lubricant characteristics and established that the light diesel fuel fractions characterize with poor lubricant characteristics. On the other hand, the main problem is layering of diesel-ethanol blends. Due to different physical and chemical properties of ethanol-diesel blends, phase separation can be observed by sometime after their mixing, as diesel fuel settles to the bottom and ethanol stays on the surface. Phase separation time depend on the ethanol content in diesel fuel (Huang et al. 2009).

Most of the authors concentrate their research on the engine performance and exhaust emission results. Therefore, the most important factor is fuel lubricating properties. Use of a too low viscosity fuel (ethanol) can provoke greater wear of precision surfaces of the plunger and the nozzle needle. The low sliding velocity and increasing load are the main reasons for marginal lubrication and resulting scuffing. To ensure tightness, very high accuracy and surface micro-geometry requirements have been rising for these components. The friction surfaces are produced by giving them $R_{a}=0.02-0.05 \mu \mathrm{m}$ roughness. When roughness is decreasing, less lubricating material penetrate into the surface. Under these conditions, even a small friction pair contact pressure increase, wear products or other reasons may cause intense adhesive wear.

Lapuerta et al. (2010a) research show that the incorporation of ethanol did not result in significant losses of lubricity until the ethanol concentration was close to $100 \%$. Additionally, in this range, increasing temperatures led to improved lubricities as a consequence of the ethanol evaporation from the lubricating layer. It was also estimated, that the lubricity of the blends decreases with the alcohol content, but this effect is partially compensated by the alcohol volatility (Lapuerta et al. 2010b). Torres-Jimenez et al. (2011b) research results presents that the addition of ethanol to diesel fuel slightly improves lubricity, as the wear scar is lower. Their results are in contrast to some authors who have shown that lubricity decreases by ethanol addition (Hansen et al. 2005; Li et al. 2005).

Armas et al. (2011) focused on a comparative experimental study for determining the effect of fuel properties on the constructive characteristics of some pieces of a current common rail injection system used in light duty diesel vehicles. Two Bosch fuel injection systems, each composed by a high pressure injection pump Bosch (270 CDI), the common rail and a Bosch piezoelectric fuel injector, were selected to be tested with two fuels. The first of the systems was tested with a low sulphur commercial diesel fuel while the second was tested with an ethanol-biodiesel-diesel blend $(7.7 \% \mathrm{v} / \mathrm{v}$ ethanol, $27.69 \% \mathrm{v} / \mathrm{v}$ biodiesel and $69.61 \% \mathrm{v} / \mathrm{v}$ reference diesel fuel). Results show that the use of the ethanol-biodiesel-diesel blend tested produced a similar effect on the durability on the injection pump components studied and on the injector nozzle as that produced by diesel fuel. In another research Armas et al. (2012) present durability test results of the high pressure fuel pump by using ethanol-diesel blend (7/7\% v/v ethanol) without biodiesel. Results show that the use of the ethanol-diesel blend tested produced a similar effect on the durability of the injection pump parts as that produced when using diesel fuel. However, the effect on the injector nozzle was dissimilar.

The results of these studies show that there is no consensus on the effect of ethanol on the fuel lubricity and reliability of fuel injection systems. 
The aim of the research is to investigate the effect of the bigger amount $(12 \% \mathrm{v} / \mathrm{v})$ of bioethanol on the durability of the components of high pressure common rail fuel pump.

\section{Materials and Methods}

A blend with $12 \% \mathrm{v} / \mathrm{v}$ ethanol and $88 \% \mathrm{v} / \mathrm{v}$ diesel fuel (E12-D) and low sulphur diesel fuel (DF) as a reference fuel were used in this study. The main properties of the tested fuels are presented in Table 1.

The experiments were conducted using a first-generation Bosch high-pressure injection pump type CR/ CP1S3/R65/10 whose main characteristics are shown in Table 2. The pump is connected to a common rail with a fuel pressure sensor. The schematic view of the experimental set-up is shown in Fig. 1.

Table 1. Fuel properties

\begin{tabular}{|l|c|c|c|}
\hline \multicolumn{1}{|c|}{ Parameter } & Diesel & E12-D & Ethanol \\
\hline Density at $40^{\circ} \mathrm{C}\left[\mathrm{kg} / \mathrm{m}^{3}\right]$ & 812.6 & 804.9 & 788 \\
\hline $\begin{array}{l}\text { Kinematic viscosity } \\
\text { at } 40{ }^{\circ} \mathrm{C}\left[\mathrm{mm}^{2} / \mathrm{s}\right]\end{array}$ & 2.06 & 1.8 & 1.2 \\
\hline Net heating value $[\mathrm{MJ} / \mathrm{kg}]$ & 42.88 & 40.56 & 26.95 \\
\hline Cetane number & 51.5 & 44.4 & 8 \\
\hline Flash point $\left[{ }^{\circ} \mathrm{C}\right]$ & 55 & 13 & 13 \\
\hline $\mathrm{C}[\% \mathrm{w} / \mathrm{w}]$ & 87 & 81.8 & 52.2 \\
\hline $\mathrm{H}[\% \mathrm{w} / \mathrm{w}]$ & 12.6 & 12.7 & 13.0 \\
\hline O $[\% \mathrm{w} / \mathrm{w}]$ & 0.4 & 5.6 & 34.8 \\
\hline $\mathrm{S}[\mathrm{ppm} \mathrm{w} / \mathrm{w}]$ & 4.1 & 3.6 & - \\
\hline Molecular weight $[\mathrm{g} / \mathrm{mol}]$ & 200 & 179.91 & 46 \\
\hline
\end{tabular}

Table 2. Main characteristics of the injection pump

\begin{tabular}{|l|c|}
\hline \multicolumn{1}{|c|}{ Parameter } & Value \\
\hline Plunger number & 3 \\
\hline Plunger diameter $[\mathrm{mm}]$ & 6.5 \\
\hline Plunger stroke $[\mathrm{mm}]$ & 10 \\
\hline
\end{tabular}

For experimental durability tests two identical fuel injection systems were prepared, which were mounted on Motorpal type NC 108-1291 test bed for a fuel injection pump. The test stand was modified to operate with dual fuel systems. One of the fuel injection systems was fed with diesel fuel from the original fuel tank of the test bench. Other fuel injection system was fuelled with E12-D blend. In order to avoid ethanol evaporation airtight tank was used for this system. Toothed belt drive was used for synchronous drive of the both high pressure fuel pumps so that both separate fuels and pumps could be evaluated simultaneously. The injection rail pressure was controlled by using pulse width modulation at $100 \mathrm{~Hz}$ to vary regulator duty-cycle while using the rail pressure sensor as feedback.

The fuel transfer pump pressure, common rail fuel pressure and fuel temperature were monitored through-

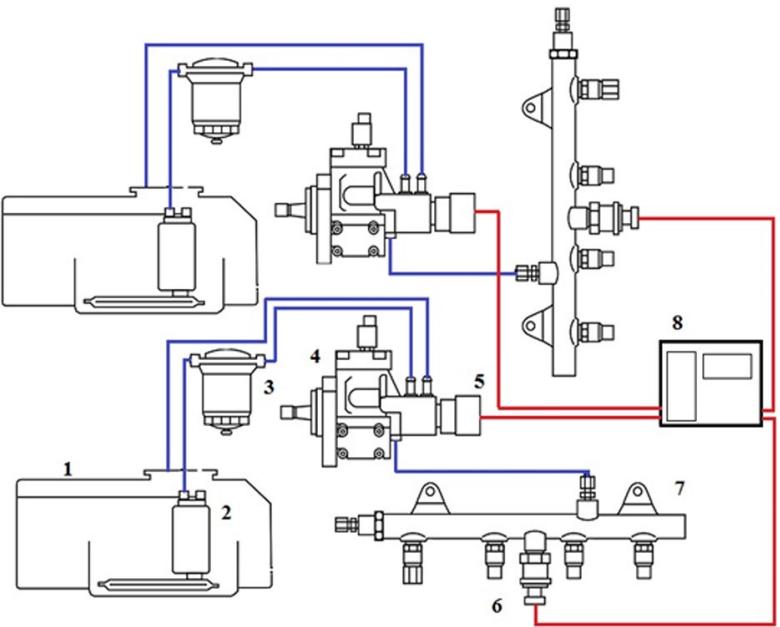

Fig. 1. Experimental test bed scheme: 1 - fuel tank; 2 - fuel transfer pump; 3 - fuel filter; 4 - high pressure pump; 5 - fuel (rail) pressure regulator; 6 - fuel pressure sensor; 7 -common rail; 8 - fuel pressure control unit

out the testing. Fuel pressure was changed every hour. The common rail fuel pressures were $20 \mathrm{MPa}, 40 \mathrm{MPa}$, $60 \mathrm{MPa}$ and $85 \mathrm{MPa}$. The fuel temperature remained below $45^{\circ} \mathrm{C}$.

Tests of the delivery performance of the both high pressure common rail pumps were carried out prior to the durability tests initiation. These tests were repeated every $50 \mathrm{~h}$. In order to control the ethanol content in the mixture its distillation was performed too.

Plungers and barrels (pump elements) surface roughness were measured to determine the effect of ethanol on the durability of the high pressure pump. Pump elements surface roughness was measured by employing measuring station MarSurf GD-25. This device allowed the measurement of surface roughness parameters along $10 \mathrm{~mm}$ with a precision of $0.001 \mu \mathrm{m}$. Two surface roughness parameters have been measured: the arithmetic mean roughness value $R_{a}$ and the mean peak-to-valley height $R_{z}$. In order to evaluate the effect of the both fuel tested on the surface roughness, difference $\Delta R_{a}$ and $\Delta R_{z}$ were determined. These differences were obtained between the final and initial mean values of the $R_{a}$ and $R_{z}$ parameters of plungers and barrels studied for each fuel respectively:

$$
\begin{gathered}
\Delta R_{a}=R_{a(\text { final })}-R_{a(\text { initial })} ; \\
\Delta R_{z}=R_{z(\text { final })}-R_{z(\text { initial })} .
\end{gathered}
$$

These values were obtained by testing the surface element along a line parallel to the axis of the plungers and barrels, including point's 1, 2 and 3 (Fig. 2). The measuring points of plungers surfaces roughness were marked accordingly S1, S2, S3 and barrel surface measuring points were marked accordingly D1, D2, D3. The experiment was repeated three times, after that, samples rotated $180^{\circ}$ degrees and experiment repeated.

In order to analysis the effect of the ethanol on the surface microstructure of the parts studied, an optical microscope MBI- 6 was used with magnification up to $200 \times$. 


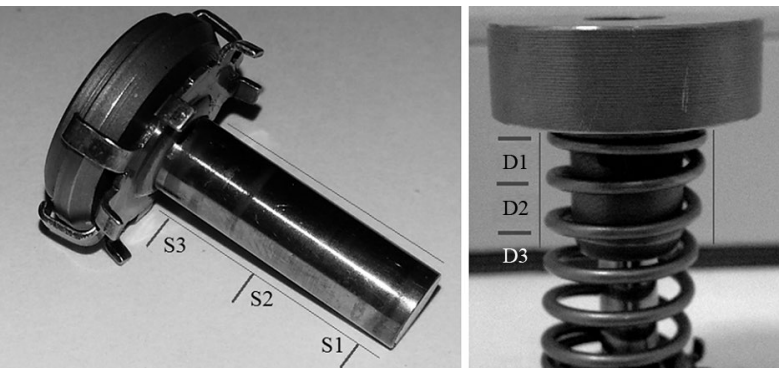

Fig. 2. Location of the points used for surface roughness and surface microstructure analysis

\section{Results and Discussions}

The results of fuel delivery tests are presented in Fig. 3, at the beginning of both fuel injection systems testing, after $50 \mathrm{~h}$ and $100 \mathrm{~h}$. As can be seen, fuel delivery of a high pressure pump running on diesel fuel remained unchanged after $100 \mathrm{~h}$. The decrease in fuel delivery in the pump running on E12-D fuel blend operating at high pressure was already observed after $50 \mathrm{~h}$ of operation. At $87.0 \mathrm{MPa}$ pressure, the decrease was equal to $4.8 \%$. After $100 \mathrm{~h}$ fuel delivery decreased by $13.8 \%, 27.1 \%$ and $28.4 \%$ at $60.0 \mathrm{MPa}$ and $80.0 \mathrm{MPa}$ and $87.0 \mathrm{MPa}$ pressure respectively. This decrease in fuel delivery shows that the pump has lost ability to work, so further tests were discontinued. These results are contrary to the research results by Armas et al. (2012) which show that the use of fuel blend with lower ethanol content $(7.7 \%$ vol.) does not signally effect the durability of the common rail fuel pump.

Pump element is one of the most loaded components in the fuel injection system. Considering the rela-
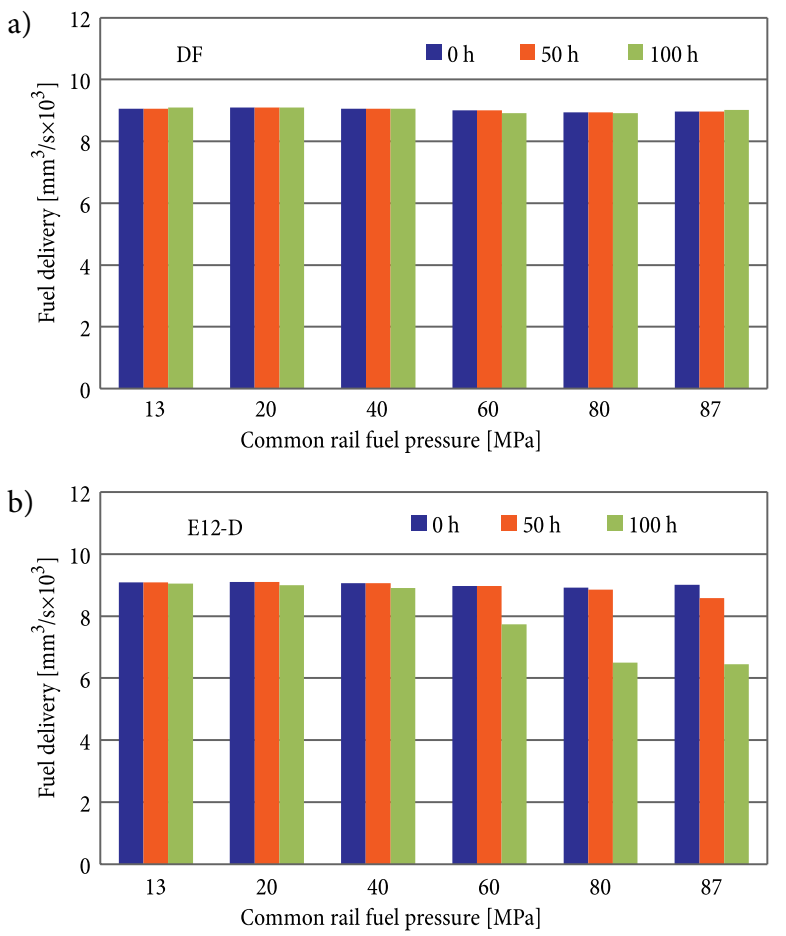

Fig. 3. High pressure pump fuel delivery versus common rail fuel pressure tively poor fuel lubricating properties it can be said that this is one of the friction pairs working under some of the most difficult conditions in the diesel internal combustion engine.

Fig. 4 shows the values of $\Delta R_{a}$ and $\Delta R_{z}$ that were obtained from each tested point of the plungers. Observing the $R_{a}$ changes (Fig. 4) in the part S1 of the plunger, it can be seen that the increase of roughness parameter $R_{a}$ of plunger surfaces of the pump running on E12-D blend was twice less than that of the pump running on diesel fuel. In the middle part of plungers S2 the increase of this parameter was only $23.9 \%$ less compared to the plungers of high pressure pump running on diesel fuel.

Meanwhile, plunger surface roughness parameter $R_{z}$ slightly increased in the zone S1, and slightly decreased in the zone S2 after 100 hours of running on diesel fuel. In pumps operated with E12-D blend, plunger surface roughness decreased in these zones by $\Delta R_{z} \approx 0.04 \mu \mathrm{m}$.

The trends of the barrel surface roughness parameters change were opposite to the plunger surface roughness change (Fig. 5). For the pump running on diesel fuel, the upper part D1 of the barrels, affected by the highest fuel pressure, increase of the surface roughness parameter $R_{a}$ was the least. In the zones D2 and D3, it increased by almost twice. For the pump running on E12-D blend, the barrel surface roughness in D1 zone even decreased, indicating more intense wear in this zone. The surface roughness parameter $R_{a}$ in $\mathrm{D} 2$ and D3 zones after 100 hours of work was also higher, as well as for the pump running on diesel fuel, but this increase was $43.5 \%$ and $27.6 \%$ lower, respectively.
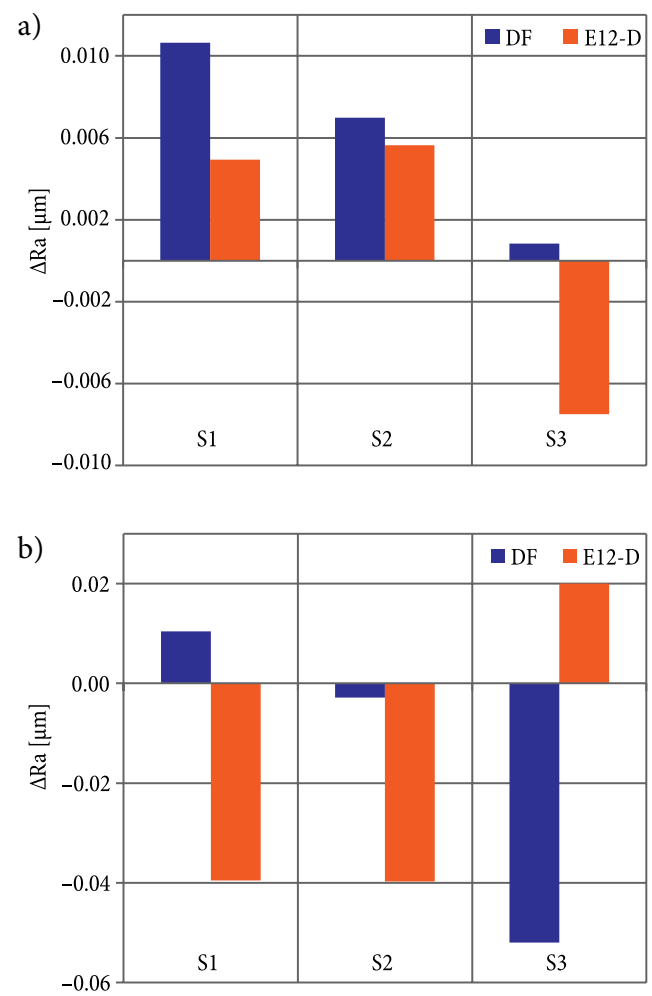

Fig. 4. Plungers surfaces $\Delta R_{a}$ and $\Delta R_{z}$ values for both tested fuels 
a)

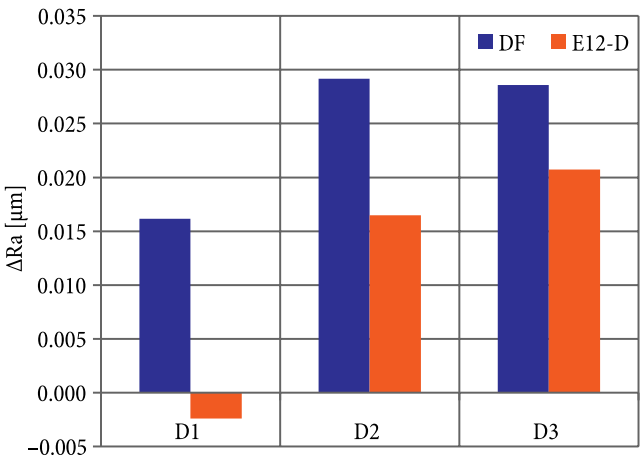

b)

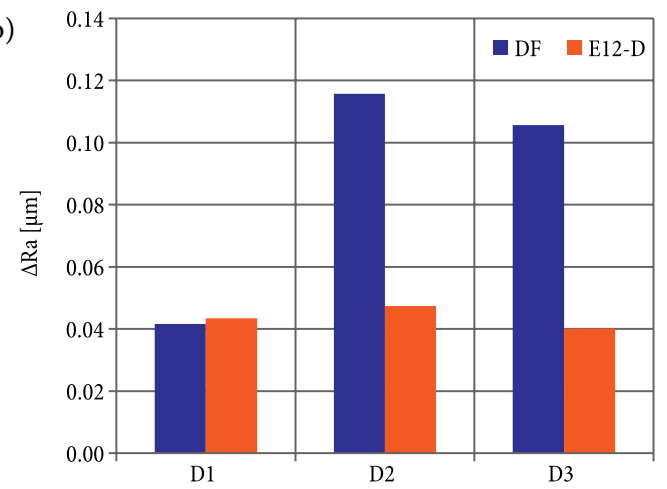

Fig. 5. Barrels surfaces $\Delta R_{a}$ and $\Delta R_{z}$ values for both tested fuels

The surface roughness parameter $R_{z}$ of the barrels increased both when running on diesel fuel and on E12D blend. In the zone D1 the increase was virtually identical in both cases. In the zones D2 and D3 parameter $R_{z}$ of barrel surfaces for the pump running on diesel fuel the increase was respectively 2.4 and 2.7 times higher than for the pump running on E12-D blend.
Assessing the images of plunger surfaces in Figs 6-7, a certain difference between the new surfaces and the surfaces after tests was observed. The obvious difference is visible when comparing friction pairs lubricated with different fuel. Ethanol containing fuel with worse lubricating characteristics did not prevent scuffing wear. When lubricating with diesel fuel, scuffing is unnoticeable in S1 part of the plunger, but when lubricating with diesel fuel and ethanol blend, scuffing is obvious. Even greater scuffing effect was observed in the part S3. In the upper part, due to good alignment of surfaces, wear of the rest part of the plunger is not intense, while a very intense wear is observed in the bottom part S3 of the plunger. When E12-D blend is used, roughness $R_{a}$ in this part decreases significantly, and although the parameter $R_{z}$ showing major roughness increases, this part is certainly affected by scuffing. The change of roughness parameters in this zone testifies about severe lubrication conditions. From the images it could be seen that when ethanol and diesel fuel mixture is used scuffing is observed on the whole surface of the plunger. Surface photos confirm the results obtained by roughness measurements which show that the wear of the plunger ends was more intensive.

Inferior lubricating properties of the blend can be interpreted by increase of the light fraction content in the fuel. Even a small change in the micro-geometric parameters may materially change the lubrication and friction pair tightness conditions. Other cause of deterioration of lubricating properties can be a substantially reduced viscosity of the mixture. Decreasing viscosity complicates ensuring a marginal layer of lubricating material between the interacting surfaces. In this case, marginal lubrication conditions can easily develop in more loaded areas. However, even pure diesel fuel does not have a very high viscosity, so its decrease by $14 \%$ does not necessarily affect lubrication.



S1 DF $0 \mathrm{~h}$



S1 DF $100 \mathrm{~h}$



S2 DF $0 \mathrm{~h}$

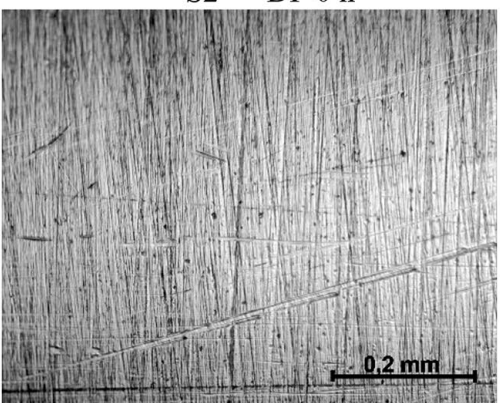

S2 DF $100 \mathrm{~h}$

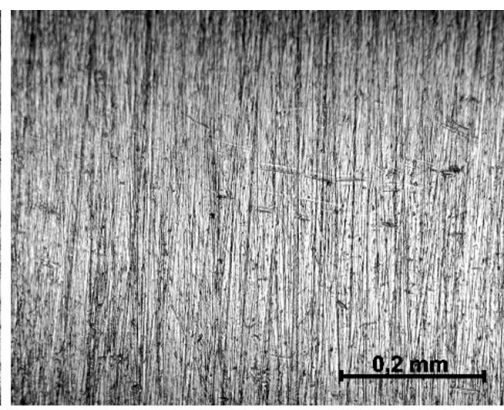

S3 DF 0h

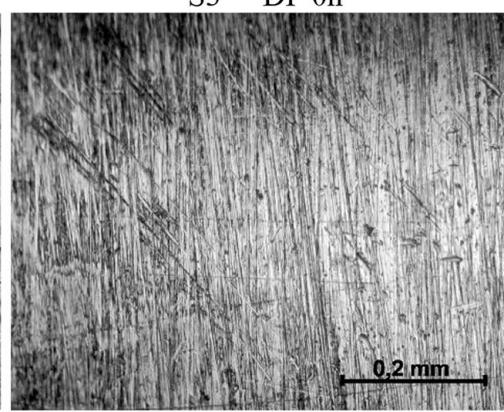

S3 DF $100 \mathrm{~h}$

Fig. 6 . The pictures of plungers surfaces S1, S2, S3, working with diesel fuel 




S1 B150 h



S1 B15 $100 \mathrm{~h}$

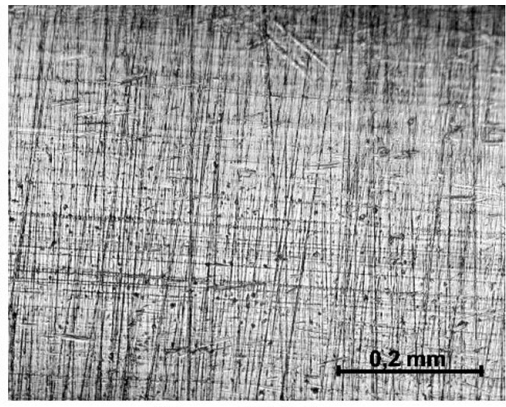

S2 B150h

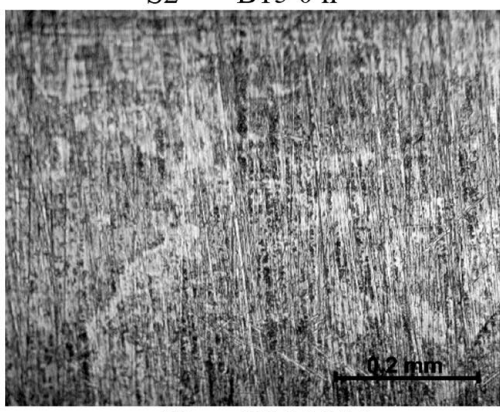

S2 B15 $100 \mathrm{~h}$

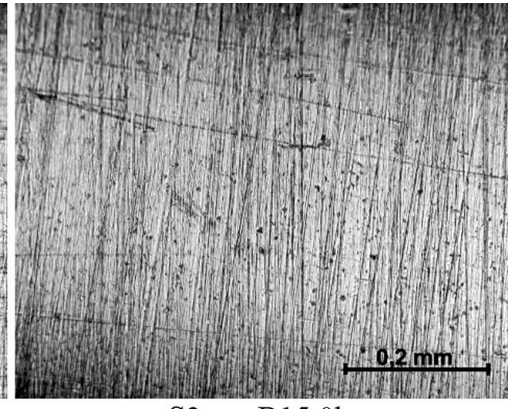

S3 $\quad$ B $150 h$

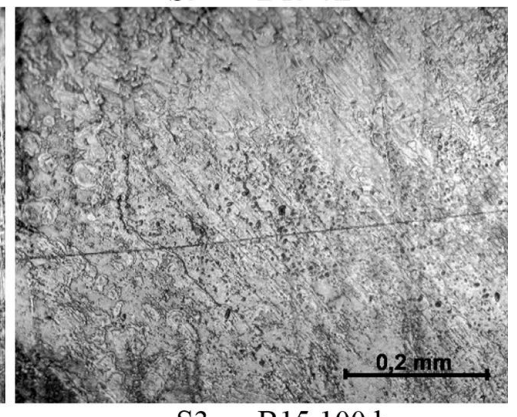

S3 B15 $100 \mathrm{~h}$

Fig. 7. The pictures of plungers surfaces S1, S2, S3, working with B15 fuel blend

\section{Conclusions}

The $12 \%$ ethanol additive in diesel fuel was tested for the effect on the durability of the common rail high pressure pump. The total fuel delivery and surface roughness indicators $\left(R_{a}\right.$ and $\left.R_{z}\right)$ as well as surface microstructures of the parts were investigated.

As the research results show, the plunger has two critical lubrication zones - the top and the bottom parts. To ensure durability of the plunger pair, elasto-hydrodynamic lubrication conditions have to be provided.

The roughness analysis of the interacting barrel surfaces showed that the most severe lubrication conditions arise in the end positions, where the slip rate decreases and the plunger changes its movement direction.

The changes of micro-geometric parameters occurring due to the wear of the plunger and the barrel are able to essentially change the conditions of tightness and lubrication of the pump element. If the pump element loses tightness, it no longer serves its direct function.

When compared to the initial conditions $(0 \mathrm{~h})$, a reduction in total fuel delivery at high pressure (87.0 MPa) of approximately 30\% was obtained when E12-D fuel blend was used. The wear of plungers and barrels when using E12-D fuel blend caused a decrease in fuel delivery after $100 \mathrm{~h}$ of operation.

\section{References}

Agarwal, A. K. 2007. Biofuels (alcohols and biodiesel) applications as fuels for internal combustion engines, Progress in Energy and Combustion Science 33(3): 233-271.

http://dx.doi.org/10.1016/j.pecs.2006.08.003

Armas, O.; Martínez-Martínez, S.; Mata, C. 2011. Effect of an ethanol-biodiesel-diesel blend on a common rail injection system, Fuel Processing Technology 92(11): 2145-2153. http://dx.doi.org/10.1016/j.fuproc.2011.06.010
Armas, O.; Mata, C.; Martínez-Martínez, S. 2012. Effect of an ethanol-diesel blend on a common-rail injection system, International Journal of Engine Research 13(5): 417-428. http://dx.doi.org/10.1177/1468087412438472

De Menezes, E. W.; Da Silva, R.; Cataluña, R.; Ortega, R. J. C. 2006. Effect of ethers and ether/ethanol additives on the physicochemical properties of diesel fuel and on engine tests, Fuel 85(5-6): 815-822.

http://dx.doi.org/10.1016/j.fuel.2005.08.027

Dernotte, J.; Foucher, F.; Hespel, C.; Houillé, S.; Mounaïm-Rousselle, C. 2011. Experimental study of the effect of fuel properties on the diesel injection process, in ECM 2011: Proceedings of the 5th European Combustion Meeting, 27 June - 1 July 2011, Cardiff, UK, 1-6.

EC. 2011. White Paper: Roadmap to a Single European Transport Area - Towards a Competitive and Resource Efficient Transport System. COM(2011) 144 final. 28.3.2011, Brussels. Available from Internet: http://eur-lex.europa.eu/ LexUriServ/LexUriServ.do?uri=CELEX:52011DC0144:EN :NOT

Edwards, R.; Larive, J. F.; Rouveirolles, P. 2001. Well-to-Wheels Analysis of Future Automotive Fuels and Power-Trains in the European Context. Well-to-Wheels report. European Commission Joint Research Center. $60 \mathrm{p}$.

Hansen, A. C.; Zhang, Q.; Lyne, P. W. L. 2005. Ethanol-diesel fuel blends - a review, Bioresource Technology 96(3): 277-285. http://dx.doi.org/10.1016/j.biortech.2004.04.007

Huang, J.; Wang, Y.; Li, S.; Roskilly, A. P.; Yu, H.; Li, H. 2009. Experimental investigation on the performance and emissions of a diesel engine fuelled with ethanol-diesel blends, Applied Thermal Engineering 29(11): 2484-2490. http://dx.doi.org/10.1016/j.applthermaleng.2008.12.016

Kajdas, C.; Majzner, M. 2001. The influence of fatty acids and fatty acids mixtures on the lubricity of low-sulfur diesel fuels, SAE Technical Paper 2001-01-1929. http://dx.doi.org/10.4271/2001-01-1929

Kim, H.; Choi, B. 2008. Effect of ethanol-diesel blend fuels on emission and particle size distribution in a common-rail 
direct injection diesel engine with warm-up catalytic converter, Renewable Energy 33(10): 2222-2228.

http://dx.doi.org/10.1016/j.renene.2008.01.002

Labeckas, G.; Slavinskas, S. 2013. Performance and emission characteristics of a direct injection diesel engine operating on KDV synthetic diesel fuel, Energy Conversion and Management 66: 173-188.

http://dx.doi.org/10.1016/j.enconman.2012.10.004

Lapuerta, M.; Armas, O.; Herreros, J. M. 2008. Emissions from a diesel-bioethanol blend in an automotive diesel engine, Fuel 87(1): 25-31. http://dx.doi.org/10.1016/j.fuel.2007.04.007

Lapuerta, M.; García-Contreras, R.; Agudelo, J. R. 2010a. Lubricity of ethanol-biodiesel-diesel fuel blends, Energy \& Fuels 24(2): 1374-1379. http://dx.doi.org/10.1021/ef901082k

Lapuerta, M.; García-Contreras, R.; Campos-Fernández, J.; Pilar Dorado, M. 2010b. Stability, lubricity, viscosity, and cold-flow properties of alcohol-diesel blends, Energy \& Fuels 24(8): 4497-4502. http://dx.doi.org/10.1021/ef100498u

Lebedevas, S.; Lebedeva, G.; Gudaityte, I. 2013. Research of characteristics of working cycle of high-speed diesel engine operating on biofuels RME-E and D-RME-E. Part 1. Indicators of fuel injection system and indicative process, Transport 28(2): 204-213. http://dx.doi.org/10.3846/16484142.2013.806346

Li, D.-G.; Zhen, H.; Xingcai, L.; Zhang, W.-G.; Yang, J.-G. 2005. Physico-chemical properties of ethanol-diesel blend fuel and its effect on performance and emissions of diesel engines, Renewable Energy 30(6): 967-976. http://dx.doi.org/10.1016/j.renene.2004.07.010

Rakopoulos, D. C.; Rakopoulos, C. D.; Giakoumis E. G.; Papagiannakis, R. G.; Kyritsis, D. C. 2014. Influence of properties of various common bio-fuels on the combustion and emission characteristics of high-speed DI (direct injection) diesel engine: vegetable oil, bio-diesel, ethanol, $n$-butanol, diethyl ether, Energy 73: 354-366.

http://dx.doi.org/10.1016/j.energy.2014.06.032

Torres-Jimenez, E.; Pilar Dorado, M.; Kegl, B. 2011a. Experimental investigation on injection characteristics of bioethanol-diesel fuel and bioethanol-biodiesel blends, Fuel 90(5): 1968-1979. http://dx.doi.org/10.1016/j.fuel.2010.11.042

Torres-Jimenez, E.; Svoljšak Jerman, M.; Gregorc, A.; Lisec, I.; Pilar Dorado, M.; Kegl, B. 2011b. Physical and chemical properties of ethanol-diesel fuel blends, Fuel 90(2): 795802. http://dx.doi.org/10.1016/j.fuel.2010.09.045 